\title{
Racism, health and constitutional recognition
}

\author{
Constitutional recognition is the next step to building a healthier nation, says the \\ Australian Indigenous Doctors' Association
}

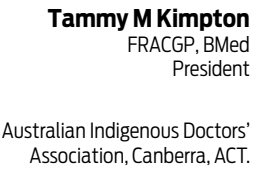

Association, Canberra, ACT.

louise@aida.org.au

doi: 10.5694/mjal4.00691
T he impacts of racism are significant, ${ }^{1}$ they matter, and racism is rightfully acknowledged as a determinant of health for Indigenous populations worldwide. $^{2}$ Recent research shows that experiences of racism and discrimination remain prevalent in Australia, through race-hate talk, race-based exclusion and physical attack. ${ }^{3}$ Correspondingly, there is evidence associating racism with poor outcomes in contemporary and historical contexts, via colonisation and oppression. ${ }^{4}$

From before birth, we are connected to family, community, culture and place. These interactions continue through life to form relationships which are crucial to belonging and to the construction of identity. This includes relationships with people and place, such as the actions and responses of others. Knowing about your own history and culture elucidates contemporary cultural ways of being, by providing a connection to the knowledge of ancestors. These connections are viewed as protective factors and contribute to building a strong sense of self and identity. ${ }^{5}$

Protective factors are inextricably linked to health and wellbeing, making the protection and promotion of culture critical to improvements in Aboriginal and Torres Strait Islander health. For Aboriginal and Torres Strait Islander people, our culture is a source of strength, resilience, happiness, identity and confidence. This philosophy embeds the importance of cultural safety into our daily practice. We do this because we know Aboriginal and Torres Strait Islander people are more likely to access, and will experience better outcomes from, services that are respectful and culturally safe. ${ }^{6}$

Thus, a focus of the work of the Australian Indigenous Doctors' Association (AIDA) is promoting culturally safe learning environments for Indigenous doctors and medical students, and culturally safe service delivery to Indigenous patients. Cultural safety is about overcoming the cultural power imbalances of places, people and policies to contribute to improvements in Aboriginal and Torres Strait Islander health. ${ }^{7}$

We work within a strengths-based framework because conveying positive messages has the potential to make a significant contribution to changing public perceptions and attitudes. ${ }^{8}$ The media is, however, not bound to report in this way; it often focuses on stories of deficit. This type of reporting can fuel racist attitudes. ${ }^{8}$

Negative framing in the media weighs into current debates about the Racial Discrimination Act 1975 (Cwlth) ${ }^{9}$ and the debate about amending Australia's constitution to recognise Aboriginal and Torres Strait Islander peoples as the First Australians. ${ }^{10}$ AIDA continues to support the maintenance of robust antiracial vilification laws as a necessary mechanism contributing to shape a health system that is culturally safe and respectful to all who access it.

Constitutional recognition is the next step in developing a healthier nation. Recognising Indigenous Australians as the First Nations peoples will enrich the identity of the nation and make significant steps towards reconciling past injustices. The current Constitution still provides a head of power that permits the Commonwealth Parliament to make laws that discriminate on the basis of race. ${ }^{10}$ The previous occasion on which protections under the Racial Discrimination Act were suspended was when activities were being implemented under the Northern Territory Emergency Response. At the time, AIDA advocated for the reinstatement of Section 9 of the Racial Discrimination Act, owing to the negative impacts that the suspension placed on the health and wellbeing of Aboriginal and Torres Strait Islander people in the Northern Territory. ${ }^{11}$ Recognising our rightful place as First Nations people in the constitution lays a strong foundation for the health, wellbeing and unity of all Australians. While it will not wash away the grave injustices of the past, with such recognition there is capacity to heal the deep wounds that affect health outcomes and continue to weigh heavily on Australia as a nation.

The medical community has a role to play in promoting Aboriginal and Torres Strait Islander recognition in the constitution. AIDA, as the peak body for Aboriginal and Torres Strait Islander doctors and medical students, will work with its peers in the medical community, as well as more broadly, to support this constitutional reform to achieve the sustainable, unifying and positive benefits that are envisaged for all Australians.

\section{Competing interests: No relevant disclosures.}

Provenance: Commissioned; not externally peer reviewed.

1 Priest NC, Paradies YC, Gunthorpe W, et al. Racism as a determinant of social and emotional wellbeing for Aboriginal Australian youth. Med J Aust 2011; 194: 546-550.

2 World Health Organization. Rio political declaration on social determinants of health. http://www.who.int/sdhconference/declaration/Rio_political_ declaration.pdf (accessed May 2014).

3 Dunn K, Forrest J, Babacan H, et al. Challenging racism: the anti-racism research project. http://www.uws.edu.au/social_sciences/soss/research/ challenging_racism/findings_by_region (assessed May 2014). 
4 Paradies Y, Harris R, Anderson I. The impact of racism on Indigenous health in Australia and Aotearoa: towards a research agenda. Discussion Paper No. 4. Darwin: Cooperative Research Centre for Aboriginal Health, 2008.

5 Social Health Reference Group for National Aboriginal and Torres Strait Islander Health Council and National Mental Health Working Group 2004. Social and emotional well being framework: a national strategic framework for Aboriginal and Torres Strait Islander peoples' mental health and social and emotional well being (2004-2009). Canberra: Department of Health and Ageing, 2004.

6 Hayman NE, White NE, Spurling GK. Improving Indigenous patients' access to mainstream health services: the Inala experience. Med J Aust 2009; 190: 604-606.

7 Australian Indigenous Doctors' Association. Cultural safety for Aboriginal and Torres Strait Islander doctors, medical students and patients. Canberra: AIDA, 2013. http://www.aida.org.au/policypapers.aspx (accessed May 2014).
8 Stoneham MJ, Goodman J, Daube M. The portrayal of Indigenous health in selected Australian media. Int Indigenous Policy J 2014; 5 (1).

9 National Congress of Australia's First Peoples. Submission to the AttorneyGeneral on the exposure draft of the Freedom of Speech (Repeal of Section 18C) Bill 2014. Racial Discrimination Act 1975 (Cth). 2014. http:// nationalcongress.com.au/wp-content/uploads/2014/04/NationalCongress-Submission-to-Exposure-Draft-of-RDA-Bill.pdf (accessed May 2014).

10 Expert Panel on Constitutional Recognition of Indigenous Australians. Recognising Aboriginal and Torres Strait Islander Peoples in the Constitution: report of the expert panel. Canberra: Commonwealth of Australia, 2012.

11 Australian Indigenous Doctors' Association; Centre for Health Equity Training, Research and Evaluation, University of New South Wales. Health impact assessment of the Northern Territory Emergency Response. Canberra: AIDA, 2010. http://www.aida.org.au/viewpublications.aspx?id=3 (accessed May 2014). 